\title{
Effect of acarbose on acute acidosis
}

\author{
C. L. McLaughlin, ${ }^{* 1}$ A. Thompson, $†$ K. Greenwood, ${ }^{*}$ J. Sherington, $\dagger$ and C. Bruce $†$ \\ ${ }^{*}$ Pfizer Animal Health, 7000 Portage Road, Kalamazoo, Ml 49001 \\ †Pfizer Animal Health, Ramsgate Road, Sandwich, Kent, CT13 9NJ, United Kingdom
}

\section{ABSTRACT}

A challenge model was used to evaluate a new approach to controlling acute acidosis. Acute acidosis reduces performance in both dairy and beef cattle and most often occurs as a consequence of ingestion of large amounts of readily fermentable starch, resulting in increased production of volatile fatty acids (VFA) and lactic acid and a reduction in ruminal $\mathrm{pH}$. Acarbose is an $\alpha$-amylase and glucosidase inhibitor that slows the rate of degradation of starch to glucose, thereby reducing the rate of VFA production and maintaining rumen $\mathrm{pH}$ at a more stable level. It is commercially available (Glucobay, Bayer, Wuppertal, Germany) and indicated for the control of blood glucose in diabetic patients. The ability of acarbose to reduce the incidence of acidosis and the comparative efficacies of acarbose, sodium bicarbonate, and monensin were tested in 3 acute acidosis challenge experiments in cattle. Rumencannulated Holstein steers were challenged with a mixture of $48.4 \%$ cornstarch, $48.4 \%$ ground corn, $2.1 \%$ sodium caseinate, and $1.1 \%$ urea with or without test substance. The challenge was administered at a rate of $12.5 \mathrm{~g} / \mathrm{kg}$ of body weight (BW) as a slurry through the cannula directly into the rumen. Ruminal $\mathrm{pH}$ was monitored at 10-min intervals throughout the study. Animals were removed from study and rumen contents replaced if they exhibited acute acidosis as defined as $\mathrm{pH}<4.5$. If acidosis was not observed within $24 \mathrm{~h}$, animals were subjected to a second challenge. Ruminal fluid samples were taken for measurement of VFA and lactate concentrations at various intervals after the challenge. In experiment 1 , the carbohydrate challenge induced acidosis in 4 of 4 control animals and 0 of 4 animals treated with 2.14 or $21.4 \mathrm{mg}$ of acarbose $/ \mathrm{kg}$ of $\mathrm{BW}$ in the challenge based on the criterion of $\mathrm{pH}<4.5$. In experiment 2 , the carbohydrate challenge induced acidosis in 4 of 7 control animals and 1 of 7 animals when $1.07 \mathrm{mg}$ of acarbose $/ \mathrm{kg}$ of $\mathrm{BW}$ was included in the challenge. In experiment 3 , acidosis was induced in 7 of 7 animals in the control, $1 \%$ sodium bicarbonate,

Received August 1, 2008.

Accepted February 9, 2009

${ }^{1}$ Corresponding author: carol.mclaughlin@pfizer.com and $12 \mathrm{mg}$ of monensin $/ \mathrm{kg}$ of dry matter intake groups and in 3 of 8 steers administered $1.07 \mathrm{mg}$ of acarbose $/ \mathrm{kg}$ of $\mathrm{BW}$ in the challenge. Increases in lactate concentrations and decreases in total VFA associated with acute acidosis were mitigated by acarbose. Thus, acarbose, an amylase and glucosidase inhibitor, prevented or reduced the incidence of acidosis in an acute challenge model in steers and was more effective than monensin or sodium bicarbonate.

Key words: acute acidosis, acarbose, dairy cow, monensin

\section{INTRODUCTION}

Rumen acidosis is a metabolic disease that negatively affects health and productivity in both beef and dairy cattle (Nocek, 1997; Owens et al., 1998) and occurs as 2 distinct syndromes: acute acidosis and subacute acidosis (SARA). Acute acidosis most commonly occurs when a diet is changed from predominantly roughage and forage to predominantly cereal grain during various stages of ruminant production; for example, in early stages of lactation and when growing animals enter the feedlot from pastures. Fermentation of large amounts of carbohydrate results in increased production of VFA that may overwhelm the capability of the rumen to maintain $\mathrm{pH}$, thus allowing growth of lactate-producing bacteria (Owens et al., 1998) in acute acidosis. High-producing dairy cows are at greater risk of SARA because of the high percentage of readily fermentable carbohydrates in rations with inadequate fiber to stimulate saliva production for buffering. Acute acidosis and SARA are most commonly distinguished using either absolute $\mathrm{pH}$ level or threshold $\mathrm{pH}$ level for a specified period. Subacute ruminal acidosis is usually defined using a cut-off $\mathrm{pH}$ value of 5.0 to 5.5 , but sometimes a $\mathrm{pH}$ value of 5.8 has been used (Nordland et al., 1995; Nocek, 1997; Garrett et al., 1999). Acute acidosis has been defined as $\mathrm{pH} 5.0$ or lower with increased lactate concentrations (Owens et al., 1998). Several methods have been used in attempts to control acidosis. Sodium bicarbonate is commonly added to rations, but the effect on $\mathrm{pH}$ is variable depending on experimental conditions (e.g., $\mathrm{Hu}$ and Murphy 2005; Paton et al., 2006). Monensin is added to almost all feedlot rations to improve feed 
efficiency with benefits of reducing acidosis likely due to decreased intake; however, effects on $\mathrm{pH}$ are only moderate or not observed under experimental conditions (Mutsvangwa et al., 2002; Benchaar et al., 2006). In addition, several yeasts have provided some protection against low pH (e.g., Bach et al., 2007; Chiquette et al., 2007; Thrune et al., 2007).

A new approach for controlling $\mathrm{pH}$ when large amounts of highly fermentable carbohydrate are fed is the use of an $\alpha$-amylase and glucosidase inhibitor, which slows the rate of degradation of starch by amylase to maltose and then glucose. Consequently, VFA production is reduced and rumen $\mathrm{pH}$ can be maintained at a higher level. A commercially available $\alpha$-amylase and glucosidase inhibitor, acarbose (Glucobay, Bayer, Wuppertal, Germany), is indicated for the control of blood glucose in diabetic patients. In the following experiments, efficacy of acarbose for controlling ruminal $\mathrm{pH}$ was tested in an acute acidosis challenge model (Nagaraja et al., 1985) and was compared with that of monensin and sodium bicarbonate in the same model.

\section{MATERIALS AND METHODS}

Pfizer Institutional Animal Care and Use Committee approval was obtained before the commencement of the study.

\section{Experiments 1 and 2}

Two experiments were conducted to evaluate the efficacy of acarbose. Glucobay tablets were ground in several batches to enable uniform mixing (Pfizer numbers UK-88,276; lot numbers 6549/174 and 8456/005 for experiments 1 and 2, respectively; Pfizer UK, Sandwich, UK). Rumen-cannulated Holstein steers were adapted to a 60:40 concentrate:roughage TMR fed twice daily and individual stall housing for the week before the first challenge. After the 2-d challenge period, the 60:40 concentrate:roughage ration was fed during a 7 -d recovery period. Within each experiment, animals were blocked by BW and randomly allocated to treatment within weight block. On d -1 , animals were equipped with a harness and backpack holding a continuously recording (every $10 \mathrm{~min}$ ) $\mathrm{pH}$ meter (WTW340, WTW Company, Weilheim, Germany). A SenTix $41 \mathrm{pH}$ probe (WTW Company) was passed through the rumen cannula and a 25-cm-long polyethylene tube into the rumen. Data from the meter were downloaded into an Excel (Microsoft Corp., Redmond, WA) spreadsheet for summary. On the first day of challenge, each animal was administered $12.5 \mathrm{~g} / \mathrm{kg}$ of BW of a mixture containing $48.4 \%$ cornstarch, $48.4 \%$ ground corn, $2.1 \%$ sodium caseinate, and $1.1 \%$ urea with or without acarbose as a slurry through the cannula (Nagaraja et al., 1985). The highest dose of acarbose $(21.4 \mathrm{mg} / \mathrm{kg}$ of BW) used in these experiments with Holstein steers was based on demonstrating an effect of $15 \mathrm{~g}$ of acarbose in a $700-\mathrm{kg}$ dairy cow (data not included). Acidosis was considered to be induced if $\mathrm{pH}$ was $<4.5$ by $12 \mathrm{~h}$ or if $\mathrm{pH}$ was $<5.0$ at $12 \mathrm{~h}$. Rumen contents were removed immediately and the rumen was inoculated with fluid from a donor animal to prevent further decline in $\mathrm{pH}$. Animals were then given ad libitum access to the TMR and longstemmed hay to facilitate recovery of rumen function. Animals not experiencing acute acidosis after the first challenge were given a second challenge $24 \mathrm{~h}$ later following the same procedure.

Rumen fluid samples were taken from the rumen via cannula just before each challenge and at 2- to 3 -h intervals until $12 \mathrm{~h}$ after each challenge for measurement of $\mathrm{pH}, \mathrm{VFA}$, and lactate. Approximately $50 \mathrm{~mL}$ of rumen fluid was removed from the rumen via a filter at the end of a sampling tube. The sample was filtered through 2 layers of cheesecloth and $\mathrm{pH}$ was measured. Samples for VFA and lactate analyses were prepared by adding 10.0 $\mathrm{mL}$ of rumen fluid to $1.0 \mathrm{~mL}$ of a solution containing a mixture of $25 \mathrm{~g} / 100 \mathrm{~mL}$ metaphosphoric acid and $1.2 \mathrm{~g} / 100 \mathrm{~mL}$ crotonic acid immediately after collection. The samples were then frozen until analysis. For analysis, each sample was thawed and a $2-\mathrm{mL}$ aliquot was centrifuged for $10 \mathrm{~min}$ at $12,000 \times \mathrm{g}$. One aliquot of the supernatant was frozen for lactate analysis and a second aliquot was transferred to an auto-sampler vial. Both aliquots were dispatched to Pfizer UK (Sandwich, UK) for D-lactate, L-lactate, and VFA analyses. Concentrations of L- and D-lactic acid were measured using reagents from a kit (Cat. no. 826, Sigma Ltd., Poole, UK) for measuring L-lactate in blood, together with Land D-lactate standards (L6402 and L0625, respectively; Sigma Ltd.) and dehydrogenase enzymes (L2625 and L2011, respectively; Sigma Ltd.). Standard curves from 0 to $100 \mathrm{~m} M$ were constructed from the standards for both D- and L-lactate and pipetted onto each test plate to allow for direct comparisons with the test samples on that plate. Duplicate $5-\mu \mathrm{L}$ aliquots of test samples and standards were aliquoted into wells on a 96 -well plate followed by $150 \mu \mathrm{L}$ of the kit reagent. Absorbance was measured on a colorimetric 96-well plate reader fitted with a filter to measure absorbance at $340 \mathrm{~nm}$. Absorbance values were measured immediately after the addition of the assay reagent and following a 15-min incubation at room temperature; then, lactate-specific absorbance was calculated as the difference between the 2 absorbance readings. This process corrected for the color of the rumen fluid and ensured that it did not lead to incorrect lactate results. Lactate concentrations in the test samples were determined from a sigmoidal 
curve fitted to the absorbance values of the standard solutions (using a proprietary software package). Volatile fatty acids were measured using a Hewlett Packard 6890 series gas chromatograph (Agilent, Santa Clara, $\mathrm{CA}$ ) fitted with an auto-sampler and flame ionization detector. Concentrations were calculated by using crotonic acid as an internal standard, and the system was calibrated using a standard solution containing acetic, propionic, butyric, isovaleric, and n-valeric acids. $\mathrm{Ru}-$ men fluid samples were not taken from animals once they developed acute acidosis and were removed from the study. Thus, summary tables include values only for animals remaining on study at each time point.

The number of ruminal contractions that occurred in a 2-min period was recorded before challenge and at the same intervals as samples were taken after each challenge. If a contraction was incomplete at the end of the 2-min period, 0.5 was added to the number of complete contractions.

The effect of treatment on the number of cows with $\mathrm{pH}<5.5$ and $<4.5$ and lactate concentrations $>25$ and $>50 \mathrm{~m} M$ were analyzed using Fisher's exact test to compare treatments versus control; two-sided $P$-values are presented. The VFA and lactate concentrations and molar percentages of acetate, propionate, and butyrate were subjected to repeated measures analysis that included treatment, time, and treatment by time interaction with animal as the subject. Daily feed intakes during the pre- and postchallenge periods were subjected to a repeated measures analysis that included day, treatment, and their interaction with animal as the subject. If a main effect or interaction was significant, least squares means were compared using orthogonal contrasts.

\section{Experiment 3}

The materials and methods were the same as for experiments 1 and 2 with the following exceptions. Two groups of animals cannulated on different dates were used. Group 1 included 13 animals with average BW of $726(\mathrm{SD}=35) \mathrm{kg}$, and group 2 consisted of 16 animals with average $\mathrm{BW}$ of $396(\mathrm{SD}=24) \mathrm{kg}$. Animals in each group were further assigned to 1 of 2 challenge batches. The first challenge batch consisted of blocks of 7 and 8 animals from groups 1 and 2, respectively; the second challenge batch consisted of blocks of 6 and 8 from groups 1 and 2, respectively. Animals within a block were randomly assigned to pen and 1 of 4 treatments, maintaining as much balance with respect to date cannulated (group) as possible. Treatments were 1) control, $\mathrm{n}=7$; 2) $1.07 \mathrm{mg}$ of acarbose $/ \mathrm{kg}$ of $\mathrm{BW}$, $\mathrm{n}=8$ (Pfizer UK-88,276 lot number 8456/005); 3) 12 $\mathrm{mg}$ of monensin $/ \mathrm{kg}$ of DMI, $\mathrm{n}=7$ (Rumensin Premix lot number 02B121, Elanco Animal Health, Division Eli Lilly, Indianapolis, IN); and 4) $1 \%$ of average DMI of bicarbonate, $\mathrm{n}=7$ (lot number 450357; Church \& Dwight/Arm \& Hammer, Princeton, NJ). Daily DMI were averaged for $\mathrm{d}-9$ to -3 (before challenge) to determine doses of sodium bicarbonate and monensin. Rumen fluid samples were taken via cannula just before and $3,6,9$, and $12 \mathrm{~h}$ after the second challenge for measurement of $\mathrm{pH}, \mathrm{VFA}$, and lactate or until acute acidosis was experienced.

The animal was considered the primary experimental unit. Each animal was classified as becoming acidotic or not, based on ruminal $\mathrm{pH} \leq 4.5$. The numbers of animals becoming acidotic were analyzed using Fisher's exact test to compare treatments versus control. For each animal, time from first challenge until the animal was first defined as acidotic was calculated, and treatments compared with controls using Wilcoxon-MannWhitney tests. The $5 \%$ significance level $(P=0.05)$ was used for all statistical tests.

\section{RESULTS}

\section{Experiment 1}

In experiment 1, 13 cannulated steers with a mean weight of $388(\mathrm{SD}=29) \mathrm{kg}$ were assigned to treatments of control $(\mathrm{n}=4), 2.14 \mathrm{mg}$ of acarbose $/ \mathrm{kg}$ of BW (n $=4)$, or $21.4 \mathrm{mg}$ of acarbose $/ \mathrm{kg}$ of $\mathrm{BW}(\mathrm{n}=5)$. None of the animals became acidotic following the first challenge (i.e., rumen $\mathrm{pH}$ values remained $>5.0$ at $12 \mathrm{~h}$ ); thus, all were administered a second challenge. Table 1 summarizes the number of animals with $\mathrm{pH}<5.0$ and $<4.5$ and total lactate concentrations $>25$ and $>50$ $\mathrm{m} M$. The $21.4 \mathrm{mg}$ of acarbose $/ \mathrm{kg}$ of $\mathrm{BW}$ treatment decreased the number of animals that met the criteria of $\mathrm{pH}<5.0$ and $\mathrm{pH}<4.5$ compared with control $(P=$ $0.01)$. The $2.14 \mathrm{mg}$ of acarbose $/ \mathrm{kg} \mathrm{BW}$ dose decreased the number of animals that met the criterion of $\mathrm{pH}$ $<4.5(P=0.03)$ but not $\mathrm{pH}<5.0(P=0.14)$. In addition, $21.4 \mathrm{mg}$ of acarbose $/ \mathrm{kg}$ of $\mathrm{BW}$ decreased the number of animals with total lactate concentrations $>25$ and $>50 \mathrm{~m} M$ compared with control $(P<0.05$ for both). In contrast, the number of animals with total lactate concentrations $>25$ or $>50 \mathrm{mM}$ in the $2.14 \mathrm{mg}$ of acarbose $/ \mathrm{kg}$ of BW group did not differ from the control group. Based on the criterion of $\mathrm{pH}<4.5$, or the criteria of $\mathrm{pH}<4.5$ and total lactate $>50 \mathrm{~m} M$, all 4 animals in the control group and no animals in either acarbose group experienced acute acidosis $(P<0.05$ compared with control for both groups).

Total lactate concentrations are illustrated in Figure 1. Contrasts for the treatment by time interaction $(P<$ $0.01)$ indicated that concentrations did not differ until 
Table 1. Number of animals with $\mathrm{pH}<5.0$ and 4.5 and $>25$ and $50 \mathrm{~m} M$ total lactate after the second challenge in experiment $1^{1}$

\begin{tabular}{lccc}
\hline & \multicolumn{3}{c}{ Treatment group } \\
\cline { 2 - 4 } & Control & $\begin{array}{c}2.1 \mathrm{mg} \text { of acarbose/ } \\
\mathrm{kg} \text { of BW }\end{array}$ & $\begin{array}{c}22.4 \mathrm{mg} \text { of acarbose/ } \\
\mathrm{kg} \text { of BW }\end{array}$ \\
\hline Item & 4 & 4 & 5 \\
Total number of steers & 4 & 1 & 0 \\
Number with $\mathrm{pH}<5.0$ & & 0.14 & 0.01 \\
$P$-value & 4 & 0 & 0 \\
Number with $\mathrm{pH}<4.5$ & & 0.03 & 0.01 \\
$P$-value & 4 & 2 & 0.05 \\
Number with lactate $>25 \mathrm{~m} M$ & 4 & 0.43 & 1 \\
$P$-value & & 0.14 & 0.05 \\
Number with lactate $>50 \mathrm{~m} M$ & 4 & 0 & 0.01 \\
$P$-value & & 0.03 & 0.03 \\
Number with $\mathrm{pH}<4.5$ and lactate $>50 \mathrm{~m} M$ & & & \\
$P$-value & & & \\
\hline
\end{tabular}

${ }^{1}$ If $50 \mathrm{~m} M$ total lactate was measured with no prior measurement of $25 \mathrm{~m} M$, then the number was the same as for $50 \mathrm{mM}$.

${ }^{2} P$-values are from Fisher's exact test compared with control for the item.

after the second challenge. Starting $6 \mathrm{~h}$ after the second challenge $(30 \mathrm{~h})$, total lactate concentrations were higher in the control than in both acarbose treatment groups, $(P<0.05)$.

The concentrations of total VFA and molar percentages of acetate, propionate, and butyrate are summarized in Figure 2. Total VFA, acetate, propionate and butyrate time and time by treatment interactions were significant $(P<0.01)$ although the overall treatment effects were not. Contrasts showed that the significance of differences between treatments varied with time. Concentrations of VFA and butyrate for all groups increased in response to each challenge and gradually declined; however, the changes were smaller for the acarbose groups. Percentage acetate and propionate decreased after challenge for the control group, and the changes were smaller for the acarbose groups.

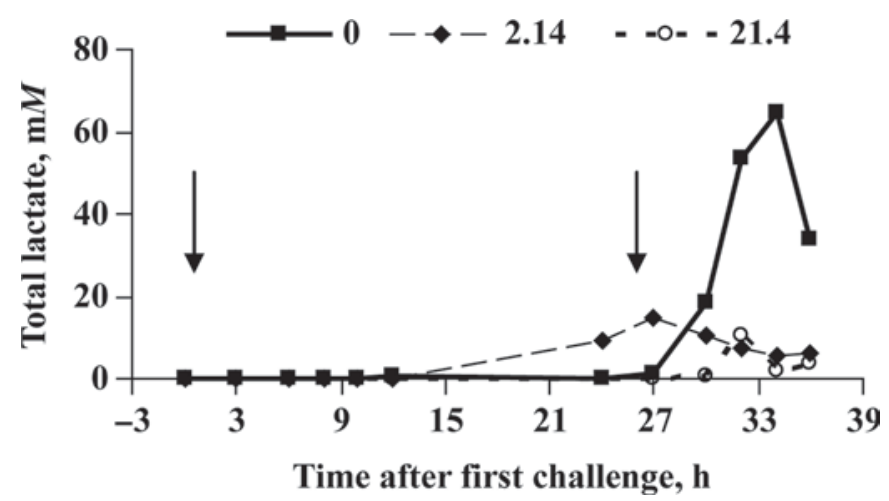

Figure 1. Lactate concentrations in experiment 1 after 2 high-carbohydrate challenges at 0 and $24 \mathrm{~h}$ (indicated by arrows) in animals receiving 0 (control), 2.14, or $21.4 \mathrm{mg}$ of acarbose $/ \mathrm{kg}$ of BW. Treatment, time, and treatment by time interactions are significant, $P<0.01$.
Numbers of rumen contractions were initially 2.75, 2.80 , and 2.00/2 min (control, $2.14 \mathrm{mg}$ of acarbose/ $\mathrm{kg}$ of $\mathrm{BW}$, and $21.4 \mathrm{mg}$ of acarbose $/ \mathrm{kg}$ of $\mathrm{BW}$, respectively) and decreased over time $(P<0.01)$ but did not differ among treatment groups such that final rates were $1.09,1.52$, and $1.80 / 2 \mathrm{~min}$, respectively.

Feed intakes before challenge did not differ among treatment groups $(16.2 \pm 0.6,16.4 \pm 0.5$, and $15.6 \pm$ $0.5 \mathrm{~kg} / \mathrm{d}$, for control, $2.14 \mathrm{mg}$ of acarbose $/ \mathrm{kg}$ of BW, and $21.4 \mathrm{mg}$ of acarbose $/ \mathrm{kg}$ of BW groups, respectively). Feed intakes gradually increased postchallenge $(P$ $<0.01)$, but the rate of increase did not differ among treatment groups $(P>0.05)$.

\section{Experiment 2}

To test the effect of a lower dose of acarbose, 14 cannulated steers with an initial BW of 455 (SD = 34) $\mathrm{kg}$ were randomly assigned within weight block to treatments of control $(\mathrm{n}=7)$ and $1.07 \mathrm{mg}$ of acarbose/ $\mathrm{kg}$ of BW $(\mathrm{n}=7)$. None of the animals became acidotic following the first challenge; that is, rumen fluid $\mathrm{pH}$ values remained $>5.0$ at $12 \mathrm{~h}$. Figure 3 illustrates 2 $\mathrm{pH}$ profiles after the second challenge for individual animals typical of each treatment group. Table 2 summarizes the number of animals that met the criteria of $\mathrm{pH}<5.0$ and 4.5 and total lactate $>25$ and $50 \mathrm{mM}$ after the second challenge. The number of animals with $\mathrm{pH}<4.5$ or 5.0 did not differ between the treatment groups. However, the number of animals with lactate $>25$ or $>50 \mathrm{~m} M$ was fewer for the acarbose group than the control group $(P=0.03)$. In addition, based on the criteria of both $\mathrm{pH}<4.5$ and total lactate $>50 \mathrm{mM}, 4$ of 7 animals in the control group and 1 of 7 animals in the acarbose group experienced acute acidosis $(P=0.08)$. 

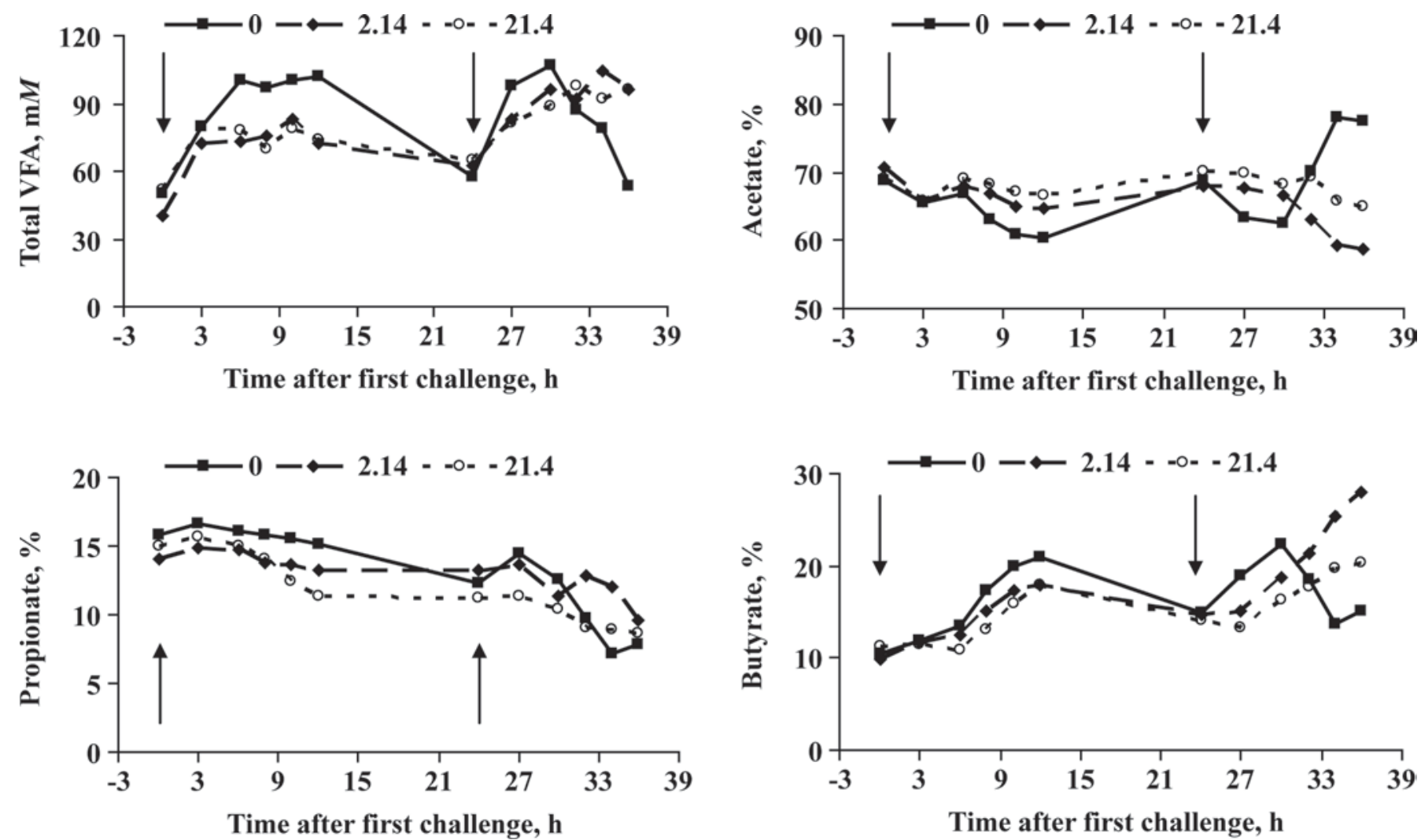

Figure 2. Total VFA concentrations and percentage acetate, propionate, and butyrate in experiment 1 after 2 high-carbohydrate challenges at 0 and $24 \mathrm{~h}$ (indicated by arrows) in animals receiving 0 (control), 2.14, or $21.4 \mathrm{mg}$ of acarbose $/ \mathrm{kg}$ of BW. Time and treatment by time interactions are significant, $P<0.01$.

Total lactate concentrations are illustrated in Figure 4. Treatment, time, and treatment by time interactions were all significant $(P \leq 0.02)$. Contrasts showed that lactate concentrations gradually increased following the second challenge for both groups, but concentrations for acarbose were lower than for control $(P<0.05)$ starting $6 \mathrm{~h}$ after the second challenge $(30 \mathrm{~h})$.

The concentrations of total VFA and molar percentages of acetate, propionate, and butyrate are illustrated in Figure 5. Time and treatment by time interaction were significant for total VFA and all molar percentages $(P \leq 0.05)$. As in experiment 1 , total VFA and percentage butyrate increased after challenge for the control group, and the increase in total VFA was less for the acarbose group for 6,9 , and $12 \mathrm{~h}$ after the first challenge and $6 \mathrm{~h}(30 \mathrm{~h})$ after the second challenge $(P<0.05)$. Percentage propionate increased and then decreased after challenge for the control group, and the increase was smaller than that of the acarbose group after both challenges at various time points $(P<0.05)$. Percentage acetate did not differ with treatment.

Numbers of rumen contractions were 1.8 and $1.4 / 2$ min for control and acarbose groups, respectively, and decreased over time $(P<0.01)$ to 1.0 and $1.2 / 2 \mathrm{~min}$ after the second challenge, but did not differ between treatments at any time point.

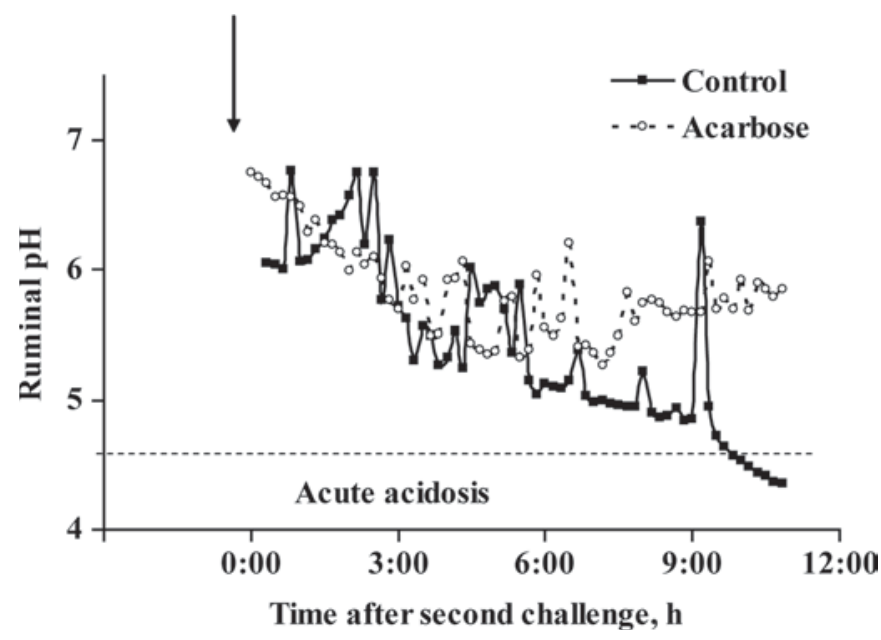

Figure 3. Representative $\mathrm{pH}$ profiles after the second high-carbohydrate challenge indicated by the arrow in 2 animals receiving either 0 (control) or $1.07 \mathrm{mg}$ of acarbose $/ \mathrm{kg}$ of $\mathrm{BW}$ in experiment 2 . 


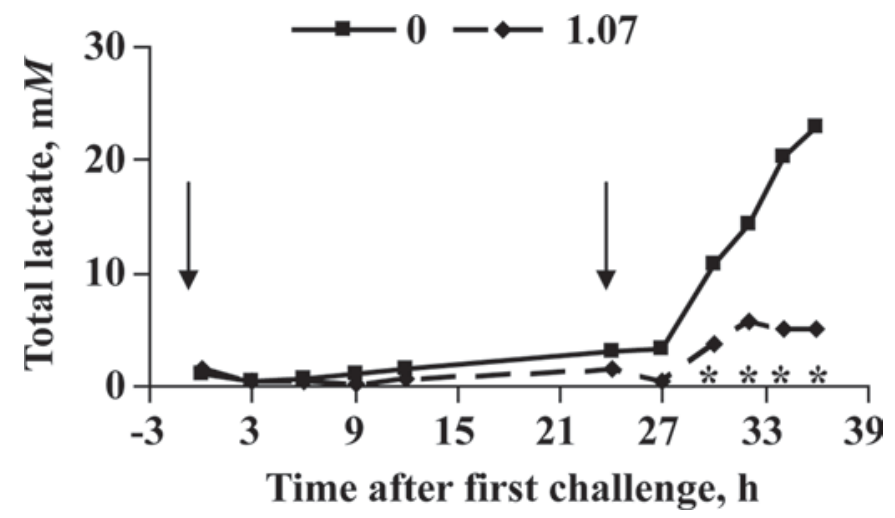

Figure 4. Total lactate concentrations after 2 high-carbohydrate challenges at 0 and $24 \mathrm{~h}$ (indicated by arrows) in animals receiving 0 (control) or $1.07 \mathrm{mg}$ of acarbose $/ \mathrm{kg}$ of $\mathrm{BW}$ in experiment 2 . Treatment, time, and treatment by time interactions are significant, $P$ $<0.03$. Asterisk $(*)$ indicates that 0 (control) different from $1.07 \mathrm{mg}$ or acarbose $/ \mathrm{kg}$ of $\mathrm{BW}$ for time point, $P<0.05$.

Mean pretreatment feed intakes did not differ among treatments $(18.0 \pm 0.06$ vs. $17.7 \pm 0.06 \mathrm{~kg} / \mathrm{d})$. Feed intakes during the posttreatment period increased over time for both groups $(P<0.01)$, and they were higher overall in the acarbose than control group $(13.9 \pm 0.05$ vs. $11.3 \pm 0.05 \mathrm{~kg} / \mathrm{d}, P<0.01$; Figure 6$)$. Contrasts for each day $(P=0.057)$ showed that intakes were higher for the acarbose group than for the control group for d 1 to 3 , indicating that feed intakes recovered more quickly in the acarbose than control group.

\section{Experiment 3}

In experiment 3 , feed intakes during a 5 -d pretreatment period were used to determine individual animal doses of monensin and sodium bicarbonate (intakes of $10.4 \pm 0.8$ and $10.2 \pm 0.8 \mathrm{~kg}$, respectively). Number of animals experiencing acidosis, median time to acidosis, and rumen fluid VFA and lactate analyses are summarized in Table 3. More animals experienced acidosis in the control, monensin, and bicarbonate groups than in the acarbose group (Fisher's exact test, $P=0.026$ for all comparisons to acarbose), and the number of animals experiencing acidosis in the control, monensin, and bicarbonate groups did not differ from each other. In evaluating time to acidosis, an animal not experiencing acidosis after the 2 challenges was assigned a
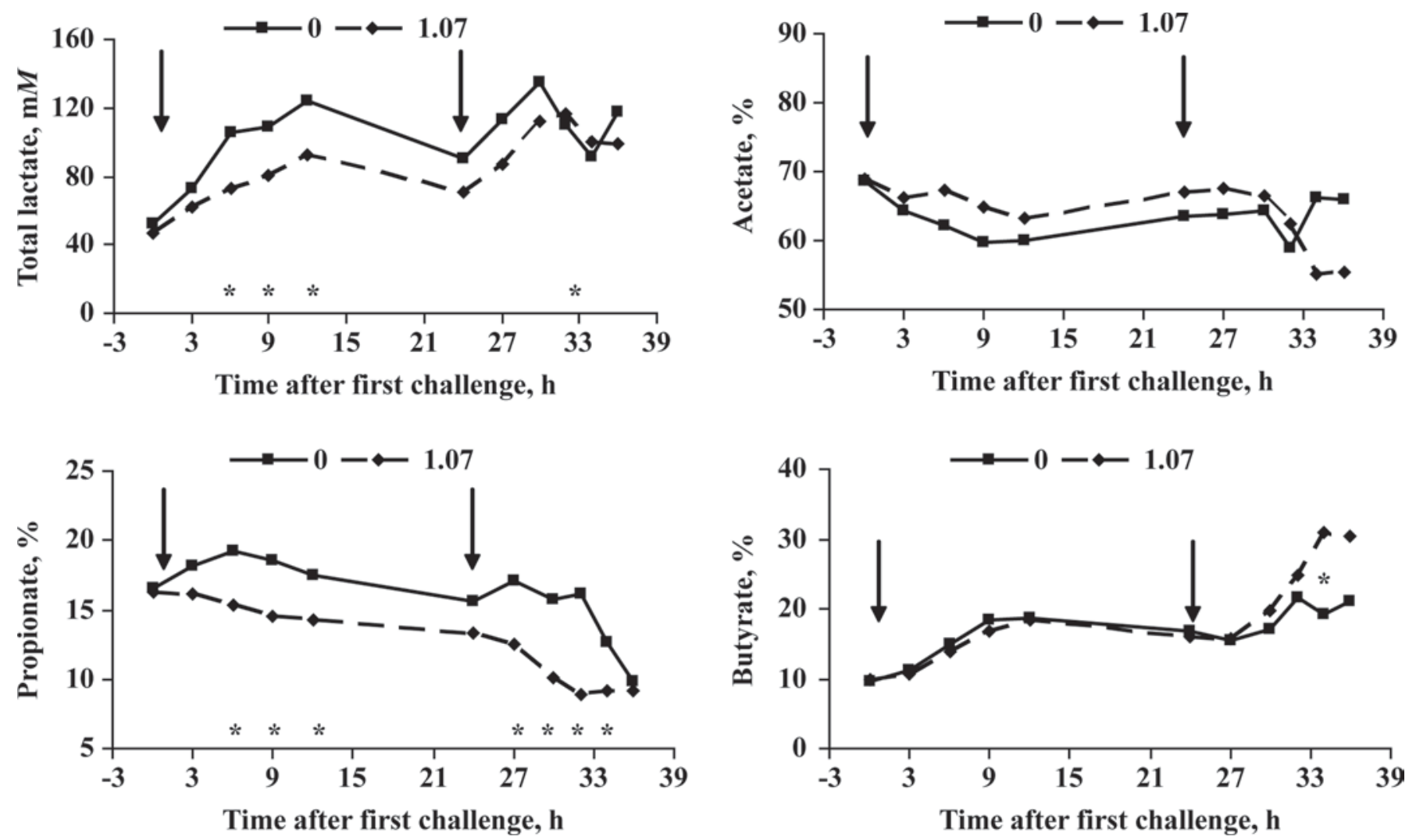

Figure 5. Total VFA concentrations and percentage acetate, propionate, and butyrate after 2 high-carbohydrate challenges at 0 and $24 \mathrm{~h}$ (indicated by arrows) in animals receiving 0 (control) or $1.07 \mathrm{mg}$ of acarbose $/ \mathrm{kg}$ of BW in experiment 2 . Time and treatment by time interactions are significant $(P \leq 0.05)$ for total VFA and percentage propionate. ${ }^{*}$ Control different from acarbose for time point, $P<0.05$. 


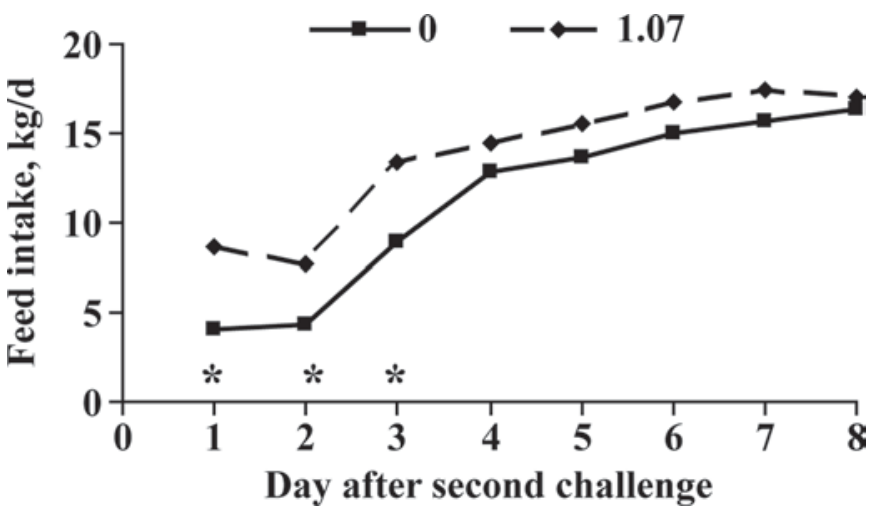

Figure 6. Feed intake starting the day after 2 high-carbohydrate challenges at 0 and $24 \mathrm{~h}$ in animals receiving 0 (control) or $1.07 \mathrm{mg}$ of acarbose $/ \mathrm{kg}$ of $\mathrm{BW}$ in experiment 2 . Treatment and time are significant $(P<0.01)$. ${ }^{*}$ Control different from acarbose for day, $P<0.05$.

time of $36 \mathrm{~h}$. The median time to acidosis differed with treatment (Wilcoxon-Mann-Whitney test, $P=0.002$ ).

The results of analysis of the last rumen fluid sample taken from each animal, which was when an animal was removed from study, either if they met the acidosis criteria or $36 \mathrm{~h}$ after the first challenge, are summarized in Table 3. The average total VFA concentrations and molar percentages of acetate and lactate concentrations were lowest in the acarbose-treated animals, which is consistent with the lower incidence of acidosis as measured by $\mathrm{pH}$ in this group.

\section{DISCUSSION}

In these experiments, the acute challenge model with highly fermentable carbohydrate as described by Nagaraja et al. (1985) reliably induced acute acidosis in control animals after the second challenge. Fifteen of 18 control animals (83\%) across the 3 experiments experienced acute acidosis if defined by ruminal $\mathrm{pH}$ $<4.5$, or 16 of 18 control animals $(89 \%)$ if acidosis is defined by ruminal $\mathrm{pH}<5$. Acidosis was accompanied by increased lactate concentrations in control animals, thus distinguishing the model from subacute acidosis in which lactate concentrations generally are not increased. The priming of the system in control animals by the first challenge was followed by a more rapid lactate production after the second challenge, indicating an earlier onset of acidosis. In addition, total VFA and molar percentages of propionate and butyrate were increased, whereas percentage acetate was decreased by the challenge. These responses are qualitatively very similar to those reported by Nagaraja et al. (1985).

Acarbose clearly prevented acute acidosis because fewer animals reached the criteria defined by ruminal $\mathrm{pH}$ and lactate levels and as indicated by effects on ruminal fluid VFA. It is hypothesized that the inhibition of $\alpha$-amylase/glucosidase activity reduced the rate of degradation of starch to glucose and thus the supply of glucose available for VFA production. Ruminal $\mathrm{pH}$ was maintained and production of lactate reduced. Acarbose reduced the response to the first challenge based on relatively higher $\mathrm{pH}$, lower total VFA levels, and lower lactose levels than for controls. It is likely that propionate and butyrate were also proportionately lower than controls because of reduced glucose availability (Reynolds, 2006). In addition, the effect was dose-related as no animals were acidotic after doses of 2.1 and $21.4 \mathrm{mg}$ of acarbose $/ \mathrm{kg}$ of BW, whereas one animal experienced acidosis at a dose of $1.07 \mathrm{mg}$ of acarbose $/ \mathrm{kg}$ of $\mathrm{BW}$ based on the criterion of $\mathrm{pH}<4.5$.

For comparison of efficacy of acarbose with that of monensin and sodium bicarbonate, the amount of each added in the challenge was calculated to be equal to the amount that would be consumed in a day based on dry matter feed intake and literature. Monensin and sodium bicarbonate are included in rations to protect against acidosis; however, they were unable to do so in this severe challenge. Other studies and models have shown, at best, moderate of control of acidosis by sodium bicarbonate and monensin. Nagaraja et al. (1985) tested several antibiotics, including monensin, and sodium bicarbonate in their acute model and showed that whereas 4 of 5 control animals became acidotic within $48 \mathrm{~h}$, acidosis was delayed to $78 \mathrm{~h}$ by inclusion of 0.66 $\mathrm{mg}$ of monensin $/ \mathrm{kg}$ of BW in the challenge. Monensin has also been tested in animals subjected to a SARA challenge. Subacute ruminal acidosis was induced after 3 to 4 wk during which the animals were administered

Table 2. Number of animals with $\mathrm{pH}<5.0$ and 4.5 and $>25$ and 50 $\mathrm{m} M$ total lactate after the second challenge in experiment $2^{1}$

\begin{tabular}{lcc}
\hline & \multicolumn{2}{c}{ Treatment group } \\
\cline { 2 - 3 } & $\begin{array}{c}1.07 \mathrm{mg} \text { of } \\
\text { acarbose/ } \\
\text { kg of BW }\end{array}$ \\
Item & $\begin{array}{c}\text { Control } \\
\text { Total number of steers }\end{array}$ & 7 \\
$\begin{array}{l}\text { Number with pH }<5.0 \\
P \text {-value }\end{array}$ & 5 & 2 \\
Number with pH $<4.5$ & 4 & 0.29 \\
$P$-value & 6 & 0.27 \\
Number with lactate $>25 \mathrm{~m} M$ & & 1 \\
$P$-value & 6 & 1 \\
Number with lactate $>50 \mathrm{~m} M$ & 4 & 0.03 \\
$P$-value & & 1 \\
$\begin{array}{l}\text { Number with } \mathrm{pH}<4.5 \text { and lactate }>50 \mathrm{~m} M \\
P \text {-value }\end{array}$ & 4 & 0.08 \\
\hline
\end{tabular}

${ }^{1}$ If $50 \mathrm{~m} M$ total lactate was measured with no prior measurement of 25 $\mathrm{m} M$, then the number was the same as for $50 \mathrm{~m} M$.

${ }^{2} P$-values are from Fisher's exact test compared with control for the item. 
Table 3. Number of animals with $\mathrm{pH}<4.5$, median time to $\mathrm{pH} 4.5$, and rumen fluid VFA and total lactate concentrations measured in the last sample taken in experiment 3 after challenge with a high carbohydrate load with no treatment (control), acarbose, monensin, or sodium bicarbonate

\begin{tabular}{lcccc}
\hline & \multicolumn{3}{c}{ Treatment group } \\
\cline { 2 - 5 } Item & Control & $\begin{array}{c}1.07 \mathrm{mg} \text { of acarbose/ } \\
\mathrm{kg} \text { of BW }\end{array}$ & $\begin{array}{c}12 \text { mg of monensin/ } \\
\mathrm{kg} \text { of DMI }\end{array}$ & $\begin{array}{c}\text { 1\% DMI sodium } \\
\text { bicarbonate }\end{array}$ \\
\hline Total number of steers & 7 & 8 & 7 & 7 \\
Number with $\mathrm{pH}<4.5$ & 7 & 3 & 7 & 7 \\
Median time to $\mathrm{pH}<4.5, \mathrm{~h}^{1}$ & 18.3 & 36 & 16.3 & 26.1 \\
Total VFA, $\mathrm{m} M$ & 123.2 & 75.3 & 101.5 & 73.7 \\
Acetate, \% & 80.9 & 66.4 & 17.7 & 79.1 \\
Propionate, $\%$ & 7.4 & 14.0 & 6.5 & 13.2 \\
Butyrate, $\%$ & 10.9 & 15.7 & & 53.3 \\
Total lactate, $\mathrm{m} M$ & 74.2 & 47.3 & & \\
\hline
\end{tabular}

${ }^{1}$ If no acidosis was experienced, a time of $36 \mathrm{~h}$ was used.

monensin as an intraruminal capsule delivering $335 \mathrm{mg}$ of monensin/d or added to the TMR at the rate of 22 $\mathrm{mg}$ of monensin/kg of DMI (Mutsvangwa et al., 2002). Under these conditions, ruminal $\mathrm{pH}$ was not affected by monensin treatment during the challenge period. In a more recent publication with monensin (Osborne et al., 2004), a dose of $22 \mathrm{mg}$ of monensin $/ \mathrm{kg}$ of DMI increased total-tract fiber digestion but did not affect ruminal $\mathrm{pH}$; thus, monensin did not control ruminal $\mathrm{pH}$ even at twice the dose used in the present study.

Efficacy of sodium bicarbonate has not been tested directly in an acute or subacute acidosis model, but the hypothesis that cows experiencing SARA have a preference for sodium bicarbonate pellets or blocks has been evaluated. Induction of SARA did not increase free-choice intake of dry sodium bicarbonate nor was ruminal pH affected (Keunen et al., 2003). Similarly, SARA-challenged cows did not show a preference for water with sodium bicarbonate added (Cottee et al., 2004). Nonchallenged cows showed no preference for sodium bicarbonate mixed in the ration or offered free choice, although the former reduced the number of long bouts of acidosis per day (Paton et al., 2006).

Several methods have been used to prevent SARA in high-producing dairy cows consuming rations with large quantities of highly fermentable carbohydrates, and step-up rations have been used to adapt feedlot cattle to high-concentrate rations. It is important that the rations have uniform particle size and adequate fiber and that the animals have continuous access to feed (Stone, 2004; Krause and Oetzel, 2005). However, there is currently no tool to prevent decreased ruminal $\mathrm{pH}$ under conditions associated with SARA. The results of these studies show that acarbose is effective in an acute model of acidosis and thus might be expected to be similarly effective at controlling $\mathrm{pH}$ under conditions of SARA at similar or lower doses. Administration of acarbose, an $\alpha$-amylase and glucosidase inhibitor, could support use of high-carbohydrate rations to maintain high milk production in dairy cows and growth in feedlot animals.

\section{CONCLUSIONS}

Acarbose is an $\alpha$-amylase/glucosidase inhibitor that controls acute acidosis by modulating the rate of VFA and lactate production. A dose as low as $1.07 \mathrm{mg}$ of acarbose $/ \mathrm{kg}$ of $\mathrm{BW}$ maintained higher $\mathrm{pH}$ values by reducing VFA and lactate production in an acute acidosis challenge model. In addition, acarbose was more efficacious than monensin or sodium bicarbonate in controlling rumen $\mathrm{pH}$.

\section{REFERENCES}

Bach, A., C. Iglesias, and M. Devant. 2007. Daily rumen pH pattern of loose-housed dairy cattle as affected by feeding pattern and live yeast supplementation. Anim. Feed Sci. Technol. 136:146-153.

Benchaar, C., H. V. Petit, R. Berthiaume, T. D. Whyte, and P. Y. Chouinard. 2006. Effects of addition of essential oils and monensin premix on digestion, ruminal fermentation, milk production, and milk composition in dairy cows. J. Dairy Sci. 89:4352-4364.

Chiquette, J., M. J. Allison, and M. A. Rasmussen. 2007. Efficacy of Prevotella bryantii 25A and a mixture of Enterococcus faecium and Saccharomyces cerevisiae to control subclinical acidosis in dairy cows. J. Dairy Sci. 90(Suppl. 1):340. (Abstr.)

Cottee, G., I. Kyriazakis, T. M. Widowski, M. I. Lindinger, J. P. Cant, T. F. Duffield, V. R. Osborne, and B. W. McBride. 2004. The effects of subacute ruminal acidosis on sodium bicarbonatesupplemented water intake for lactating dairy cows. J. Dairy Sci. 87:2248-2253.

Garrett, E. F., M. N. Pireira, K. V. Nordland, L. E. Armentano, W. J. Goodger, and G. R. Oetzel. 1999. Diagnostic methods for the detection of subacute ruminal acidosis in dairy cows. J. Dairy Sci. 82:1170-1178.

Hu, W. P., and M. R. Murphy. 2005. Statistical evaluation of early- and mid-lactation dairy cow responses to dietary sodium bicarbonate addition. Anim. Feed Sci. Technol. 119:43-54.

Krause, K. M., and G. R. Oetzel. 2005. Inducing subacute ruminal acidosis in lactating dairy cows. J. Dairy Sci. 88:3633-3639.

Keunen, J. E., J. C. Plaizier, I. Kyriazakis, T. F. Duffield, T. M. Widowski, M. I. Lindinger, and B. W. McBride. 2003. Effects of subacute ruminal acidosis on free-choice intake of sodium bicarbonate in lactating dairy cows. J. Dairy Sci. 86:954-957. 
Mutsvangwa, T., J. P. Walton, J. C. Plaizier, T. F. Duffield, R. Bagg, P. Dick, G. Vessie, and B. W. McBride. 2002. Effects of a monensin controlled-release capsule or premix on attenuation of subacute acidosis in dairy cows. J. Dairy Sci. 85:3454-3461.

Nagaraja, T. G., T. B. Avery, S. J. Gilitzert, and D. L. Holman. 1985. Effect of ionophore antibiotics on experimentally induced lactic acidosis in cattle. Am. J. Vet. Res. 46:2444-2452.

Nocek, J. E. 1997. Bovine acidosis: Implications on laminitis. J. Dairy Sci. 80:1005-1028.

Nordland, K. V., E. F. Garrett, and G. R. Oetzel. 1995. Herd-based rumenocentesis: A clinical approach to the diagnosis of subacute rumen acidosis. Compend. Contin. Educ. Pract. Vet. 17:S48S56.

Osborne, J. K., T. Mutsvangwa, O. Alzahal, T. F. Duffield, R. Bagg, P. Dick, G. Vessie, and B. W. McBride. 2004. Effects of monensin on ruminal forage degradability and total tract diet digestibility in lactating dairy cows during grain-induced subacute ruminal acidosis. J. Dairy Sci. 87:1840-1847.
Owens, F. N., D. S. Secrist, W. J. Hill, and D. R. Gill. 1998. Monensin and abomasal protein passage of steers. J. Anim. Sci. 76:275286.

Paton, L., K. Beauchemin, D. Viera, and M. von Keyserlingk. 2006. Use of sodium bicarbonate, offered free choice or blended into the ration, to reduce the risk of ruminal acidosis in cattle. Can. J. Anim. Sci. 86:429-437.

Reynolds, C. K. 2006. Production and metabolic effects of site of starch digestion in dairy cattle. Anim. Feed Sci. Technol. 130:78-94.

Stone, W. C. 2004. Nutritional approaches to minimize subacute ruminal acidosis and laminitis in dairy cattle. J. Dairy Sci. 87(E Suppl.):E13-E26.

Thrune, M., A. Bach, M. Ruiz-Moreno, M. D. Stern, and J. G. Linn. 2007. Effects of Saccharomyces cerevisiae on ruminal pH and microbial fermentation in lactating dairy cows. J. Dairy Sci. 90(Suppl. 1):172. (Abstr.) 